\title{
Nonlinear Numerical Modelling of Basalt Rebar Reinforced Concrete Structures
}

\author{
Jānis Šliseris, Līga Gaile, Leonīds Pakrastiṇš, Kārlis Rocēns \\ Riga Technical University, Faculty of Civil Engineering, Institute of Structural Engineering and Reconstruction, \\ Address: Kìpsalas street 6, Rīga, LV-1048, Latvia.
}

\begin{abstract}
The ever increasing tendency of more complex architecture and increasing use of basalt fibers in concrete, mainly due to corrosion resistance, requires a suitable, accurate and computationally efficient numerical method for m.odelling of mechanical behavior. A novel numerical modelling methodology for basalt fiber reinforced concrete structures is proposed. In this paper, the main focus is on modelling concrete beams with basalt longitudinal rebars and steel shear rebars. The proposed method is based on two step simulation method. On the first step a database of flexural stiffness depending on stress-strain state is created using non-linear simulations with continuum finite elements. The database of flexural stiffness is used in second step by performing nonlinear beam finite element simulation of frame structures. The numerical method showed good agreement with experimental results. The use of pre-computed database of flexural stiffness significantly accelerate non-linear simulations and whole building can analyzed by taking into account material non-linearity.
\end{abstract}

Keywords: Basalt fibers, non-linear FEM, concrete structures.

\section{INTRODUCTION}

Basalt fiber reinforced concrete have increasing popularity due to corrosion resistance, high tensile strength to weight ratio and good non-magnetization properties. Basalt fiber use in structures where corrosion effects are significant, can be economically and environmentally beneficial. The precise and optimal structural design of basalt fiber reinforced concrete requires an efficient and robust numerical modeling technique.

Numerical modeling of basalt fiber reinforced concrete is complex process. The numerical model must take into account the material non-linearity. Experimental investigations shows that, even for the deflections smaller that serviceability limit state, there are observed highly non-linear material behavior [1].

The flexural testing of single span basalt fiber reinforced concrete beam showed a complex cracking pattern and load-displacement character [1,2,3]. Meanwhile, slip between basalt rebar and concrete for certain circumstances can be observed experimentally [1]. In case of multi-span basalt rebar reinforced concrete plate there are observed bending moment redistribution and highly non-linear material behavior [4].

Those material nonlinearities can be taken into account by appropriate material constitutive law. A thermodynamically consistent non-local damage model for concrete are proposed by [5]. This material model is used in this work. In case of cyclic loading, stiffness recovery and frictional sliding between fiber and concrete, there are proposed a special constitutive model [6]. A virtual crack monitoring starting from micro-cracks to macroscopic cracks can be achieved by using a combined XFEM- damage mechanic approach [7]. An effective way for calculation of material parameters that are necessary in continuum damage model by using fracture mechanic approach are presented in paper [8]. A convergence problems may arise when non-linear concrete material model is used, therefore non-local theories are recommended. A consistent scheme for calculation of tangential stiffness for non-local damage models are prosed in work [9].

Real-size structures can be mathematically modelled by using extended multi-scale finite element (EMFEM) model, or other sub-structuring methods $[10,11,12,13]$. In those publications, mainly continuum based finite elements are used. Currently, there are lack of information on modeling using beam finite elements on coarse scale and continuum elements on fine scale. For concrete structures beam finite elements have been widely used to get the whole building structural response. In this work there are proposed a modelling framework of concrete structures with basalt rebars. This technique is based on two scale simulations. On the fine scale simulations, a database with precomputed stiffness characteristics of concrete elements are obtained, depending on deformation state. Furthermore, this database is used for numerical modeling of whole structure on coarse scale by using non-linear beam finite elements. 


\section{NUMERICAL MODELING}

Appropriate numerical modelling technique is dependent on the structural behaviour. For slender beam or frame structures here are proposed a special semi-analytical method that take into account bending moment and axial force when estimating flexural stiffness. When the beam span to cross section height ratio is less than 10 then it is recommended to use EMFEM approach to generate the database with flexural stiffness for necessary cross section. In case of large building frame, both methods can be combined to get maximal performance.

Material constitutive model for concrete is similar as described in publication [5], that include separate damage variable for tension cracking $d_{t}$, and for compression damage $d_{c}$. As indicated in experimental testing of basalt rebars, they behave nearly linear elastic up to failure [3]. Therefore linear elastic model is used for basalt rebars.

For the tension zones the stiffness was reduced with multiplier $\left(1-d_{t}\right) *\left(1-d_{c}\right)$, but in compression zones $\left(1-d_{c}\right)$ [5]. The evolution of damage variables was defined by exponential laws. For more details see [5].

For beams with complicated geometry, where high stress gradients can appear, it is necessary to use embedded window method [11]. In this case the beam finite element is joined with linear elastic extension (with length $L^{*}$ ) in both ends. This method is recommended for the cases when hypothesis of flat cross sections is not valid.

Concrete is modelled with continuum based finite elements. In this paper a plane stress 4 node finite elements are used. Rebars are modelled by using 2 node link type finite elements.

The obtained database are used in non-linear beam finite element. Only material non-linearity is used for small strain theory.

Extended multi-scale approach

Secant stiffness matrix of beam FE is obtained by performing fine scale simulation with plane stress non-linear finite elements. For beam element with $\mathrm{N}$ degrees of freedom (DOF), the nodal displacement vector $\boldsymbol{d}^{0}=\left\{U^{1}, U^{2}, \ldots, U^{N}\right)$. From structural mechanics and finite element definition it is clear that $\mathrm{i}$-th column in stiffness matrix is defined by nodal forces of beam finite element from appropriate unit ith DOF []. Therefore N+1 load cases are necessary for calculation of stiffness matrix of beam finite element. i-th load case is defined by following displacements applied to nodes of finite element $\boldsymbol{d}^{i}=$ $\left\{U^{1}, U^{2}, U^{i-1}, 0, U^{i+1} \ldots, U^{N}\right)$. The reaction forces from nodal displacements on coarse scale nodes are denoted in following way $F^{i}=F\left(d^{i}\right)=$ $\left\{F^{i, 1}, F^{i, 2}, \ldots, F^{i, N}\right\}$. Coefficients of secant stiffness matrix are obtained using following expression:

$$
K_{i, j}=\frac{F^{0, j}-F^{i, j}}{\left\|d^{0}\right\|},
$$

where index i- indicate load case number and $\mathrm{j}$ component of reaction force vector.

For relatively slender structures, instead of calculation of whole stiffness matrix, only flexural stiffness EI, axial stiffness EA and shear stiffness GA are necessary to compute. Using appropriate beam theory, for example classical or Timoshenko, stiffness matrix can be assembled.

For slender structures where only EI and EA are important a special semi- analytical approach are presented in next sub-chapter.

Semi-analytical approach

This method is recommended for the structures that have tendency to fail due to bending moment.

Due to non-linear stress-strain relationship the position of neutral axis of cross section is dependent on bending moment and axial force acting in this cross section. It is assumed that classical EulerBernoulli hypothesis of flat cross sections are true. Using this hypothesis, deformation field of cross section can be described with tension strains $\varepsilon_{s t}$, compression strains $\varepsilon_{s p}$, and position of neutral axis $X$ (see figure 1). Those three unknowns are calculated by using three non-linear integral equations $R_{1}, R_{2}, R_{3}$.

The first equation states the moment equilibrium of internal stress resultant and bending moment $\mathrm{M}$ in current cross section:

$$
R_{1}=\int_{-X}^{H-X} \sigma(y) * y * b(y) * d y-M=0
$$

For practical calculations the cross section is divided in many layer (usually 30 to 50 ), where i-th layer distance to neutral axis is $y_{i}$ and normal stress in this layer is $\sigma_{i}$, area of i-th layer is $A_{i}$. Total height of cross section is $\mathrm{H}$.

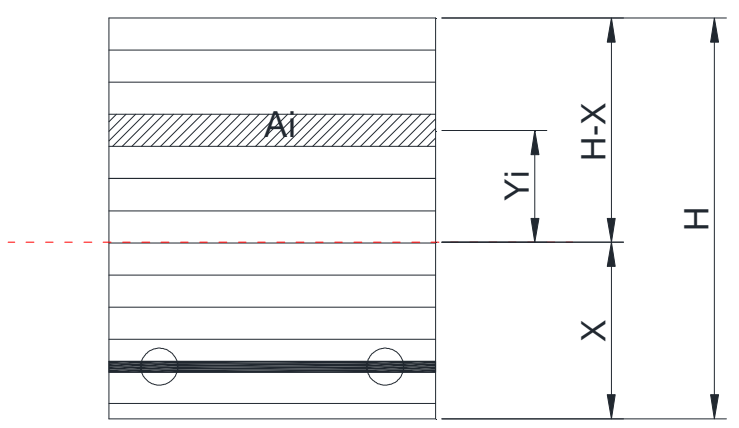

Figure 1. Multi-layer structure of reinforced concrete with smeared rebar's layer. layer.

Rebars are replaced with equal area smeared

Second equation is obtained by using equilibrium of axial forces:

$$
R_{2}=\int_{-X}^{H-X} \sigma(y) * b(y) * d y-N
$$


The third equation is obtained by using assumption that strains on neutral axis $\varepsilon_{N}$ are produced only by axial force:

$$
R_{3}=\int_{-X}^{H-X} E(y) * \varepsilon_{N} * b(y) * d y-N
$$

where $E_{i}$-modulus of elasticity of i-th layer.

$\varepsilon_{N}$ is calculated by using linear interpolation of strains through the thickness of cross section:

$$
\varepsilon_{N}=\frac{\varepsilon_{S t} * H+X *\left(\varepsilon_{S p}-\varepsilon_{S t}\right)}{H}
$$

Resulting system of three non-linear equations is solved by Newton-Raphson iterative method. When the strains and position of neutral axis are known, then flexural stiffness EI and axial stiffness EA are computed and used in non-linear beam finite element.

Non-linear beam finite element

In this work a typical 2 node beam finite element with 3 DOF (two translations and one rotation) per node are used. Total load is divided in $N_{\text {steps }}$ load steps. Within each load step there are performed a modified Newton-Raphson iterations. Once the convergence norm of residual vector $R$ is less then tolerance than iterations stops and algorithm moves to next load step.

$$
R=F_{\text {int }}-F_{\text {ext }}
$$

where $F_{\text {int }}$ - internal forces in nodes, $F_{\text {ext }}$ - external forces in nodes.

The secant stiffness matrix $C_{S}$ is computed using Timoshenko or Euler- Bernoulli theory, depending ratio between span of beam and height of cross section:

$$
\boldsymbol{C}_{\boldsymbol{s}}=\boldsymbol{F}(E I, G A, E A)
$$

The convergence difficulties are reduced by using non-local theory. Instead of local flexural stiffness, the smeared flexural stiffness $\widetilde{E I}$ is used. This can solve the mesh dependency problem and also can include the tension stiffening effects.

\section{RESULTS AND DISCUSSION}

The numerical results are validated using experimental measurements from publications [3,4]. Four point bending test of single span $3 \mathrm{~m}$ long beam and flexural test of two span beams (each span $2 \mathrm{~m}$ long) are analysed.

\section{Single span beam in four point bending}

Experimental data of four point bending test was taken from publication [3]. Beam was made using C30/37 concrete, with cube compresive strength 52.3MPa, modulus of elasticity $33.8 \mathrm{MPa}$ and tensile strength 3.6 MPa.Tensile reinforcement was made of $5 \varnothing 9 \mathrm{~mm}$ basalt rebars. Tensile strength of basalt rebars was $1485 \mathrm{MPa}$, modulus of elasticity 56.3 $\mathrm{GPa}$, and ultimate strain $2.62 \%$.

In compression zone $2 \varnothing 8 \mathrm{~mm}$ B500SP steel rebars was used. Shear reinforcement was made of $\varnothing 8 \mathrm{~mm}$ steel rebars with $100 \mathrm{~mm}$ step. Height and width of cross section was 300 and $200 \mathrm{~mm}$, respectively. Distance from center of rebars to surface of beam was $30 \mathrm{~mm}$. Total length of beam was $3050 \mathrm{~mm}$, distance between supports $2700 \mathrm{~mm}$ and distance between applied loads was $900 \mathrm{~mm}$. Since the ratio beween span and cross section height is 9 , extended multiscale approach was used.

The load deflection curve is shown in figure 2 . There was performed a 3 alternative numerial simulations- full finite element simulation, extended multiscale with embedding window length $L^{*}=0$ and extended multiscale with embedding window length $L^{*}=90 \mathrm{~mm}$. Simulations were done up to servicability limit state (assumed L/250). Up to 10 $\mathrm{KN}$ load the full scale finite element simulation showed better agreement with experiments. The simulation with extra window $L^{*}=90 \mathrm{~mm}$, showd slightly overestimated stiffness comparing to experiments, when load exceeds $25 \mathrm{KN}$. The best agreement with experimetns was showd simulations with window $L^{*}=0$, when load exceeds $25 \mathrm{KN}$.

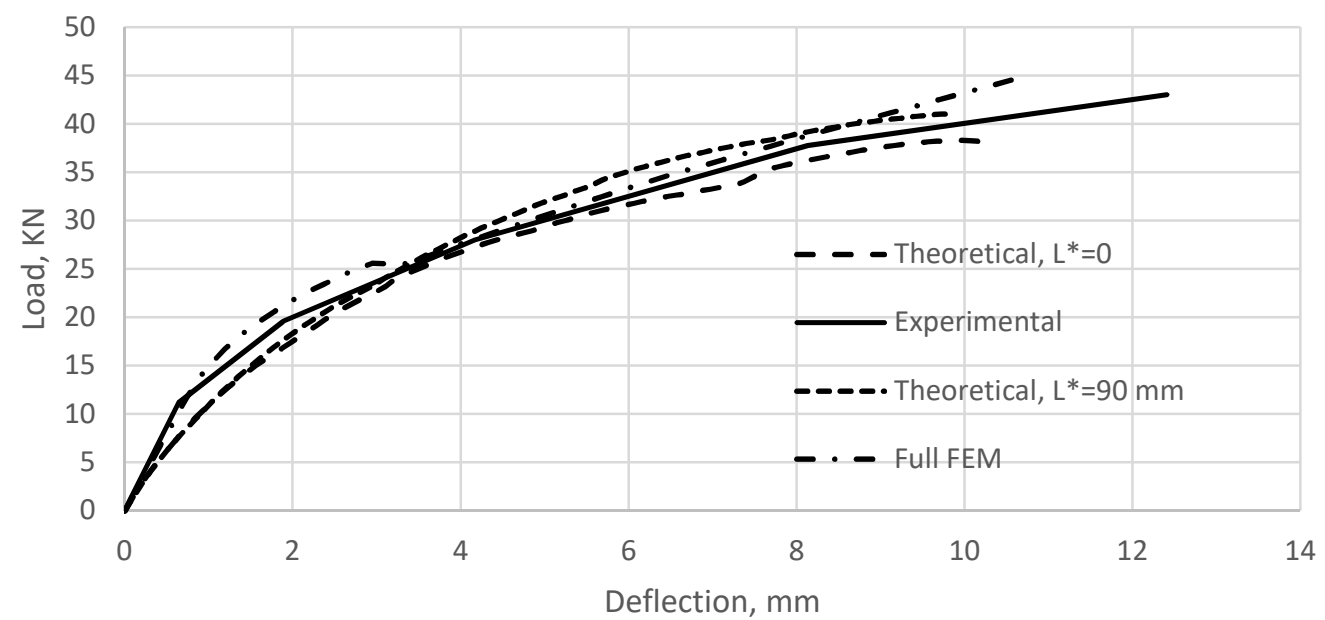

Figure 2. Validation of model with experimental data, load-deflection curve, for beam with 5 basalt fibers, diameter 9 mm. 


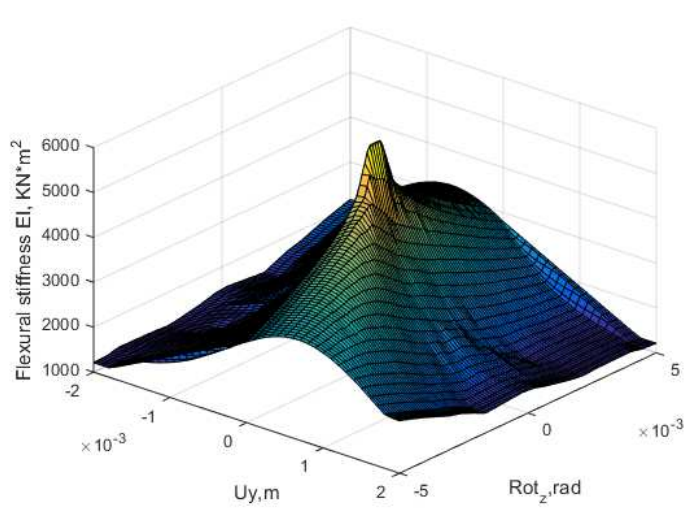

Figure 3. 3D visualization of flexural stiffness EI, depending displacement degrees of freedom of beam FE. Length of finite element was $250 \mathrm{~mm} . L^{*}=0$

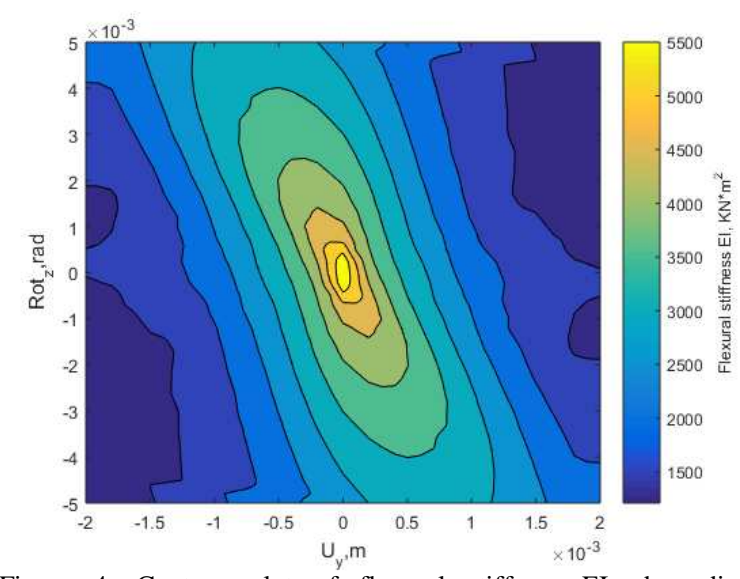

Figure 4. Contour plot of flexural stiffness EI, depending displacement degrees of freedom of beam FE. Length of finite element was $250 \mathrm{~mm} . L^{*}=0$

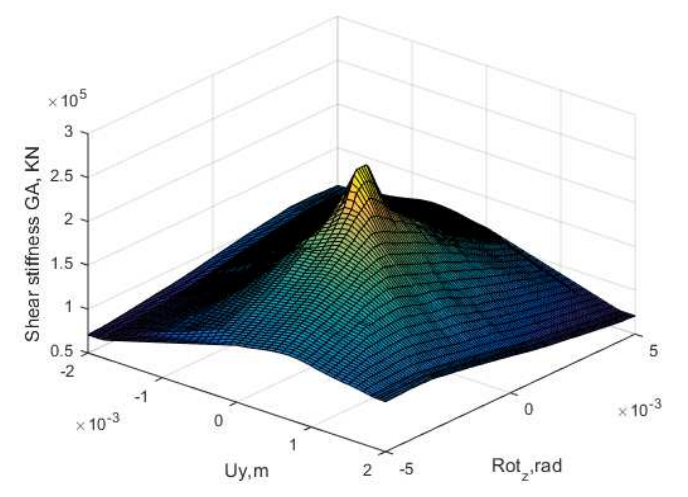

Figure 5. 3D visualization of shear stiffness GA, depending displacement degrees of freedom of beam FE. Length of finite element was $250 \mathrm{~mm} . L^{*}=0$

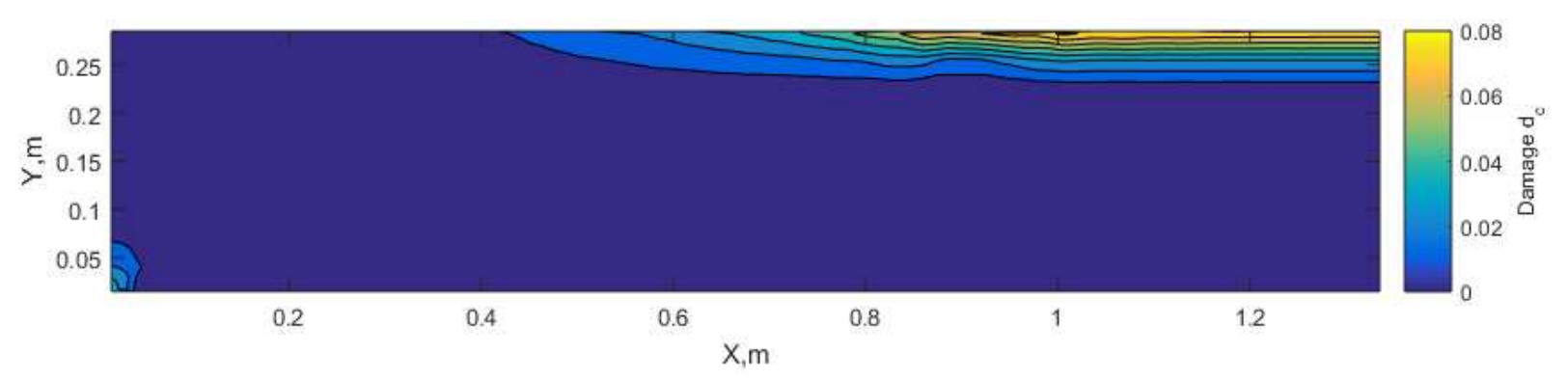

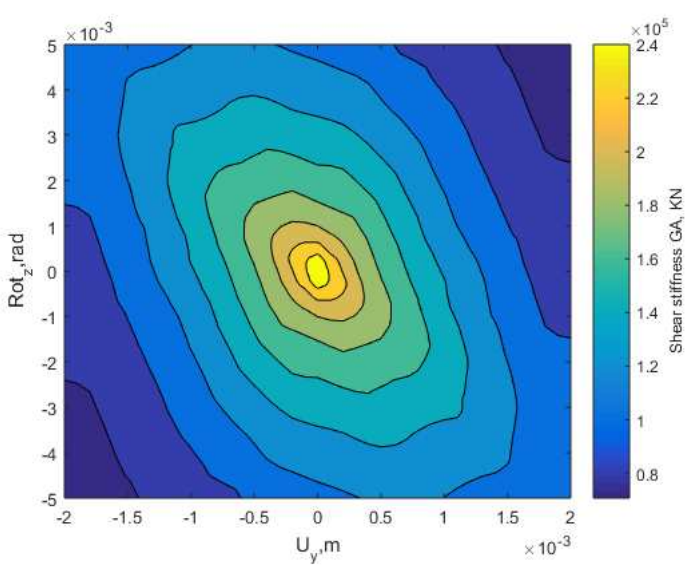

Figure 6. Contour plot of shear stiffness GA, depending displacement degrees of freedom of beam FE. Length of finite element was $250 \mathrm{~mm} . L^{*}=0$

Databases of flexural and shear stiffness for beam finite element with length $250 \mathrm{~mm}$ and zero extra window length are shown in figures 3-6. Maximal flexural and shear stiffness $6000 \mathrm{KN} * \mathrm{~m}^{2}$ and $300000 K N$, respectively, was observed at nearly zero degrees of freedom. The overall character of shear and flexural stiffness showed a similar tendency.

The visualization of damage evolution is showed in figures 7-8. The damage is represented by damage variable, where 0 indicates no damage and 1 complete damaged area. Experimental observation of damage evolution for similar beams are shown in figure 9. The tensile crack-damage propagation are similar with experimental data. The symmetry of structure was taken into account and only half of beam was modelled.

Figure 7. Damage variable in compression $d_{c}$. 


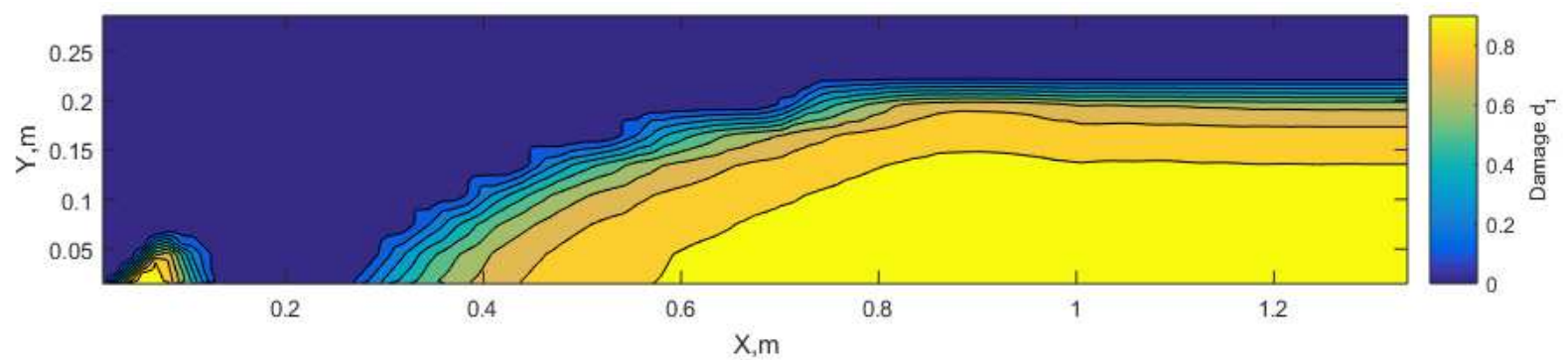

Figure 8. Damage variable in tension $d_{t}$.

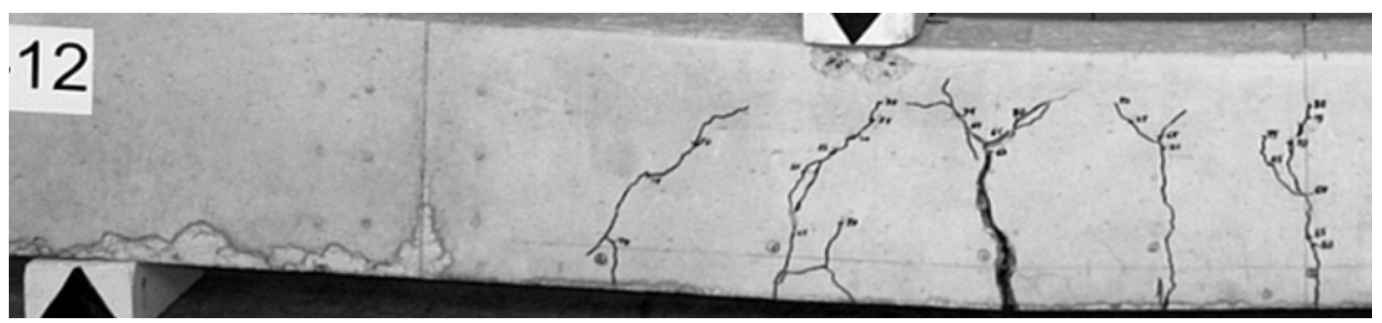

Figure 9. Typical experimental observation of basalt beam failure in four-point bending (figure taken from [1]).

\section{Two- span beam}

The numerical model was validate with continuous two $2000 \mathrm{~mm}$ span slab. All details are give in publication [4]. A concentrated loads were applied in the middle of each span. Thickness of slab was $150 \mathrm{~mm}$, width $500 \mathrm{~mm}$. Material properties were similar as for single span beam in previous section. Two cross sections were tested. The first cross section was made of $5 \varnothing 10 \mathrm{~mm}$ basalt rebars and denoted as C-B-OO. The second cross section was made of $3 \varnothing 8 \mathrm{~mm}$ basalt rebars and denoted as C-BUU. Since the span to thickness ratio is 13.3 , a semianalytical approach are used for numerical simulations. In figure 10 is show the loaddisplacement curve that shows good agreement between experiments and simulations even for load much higher than serviceability limit state.

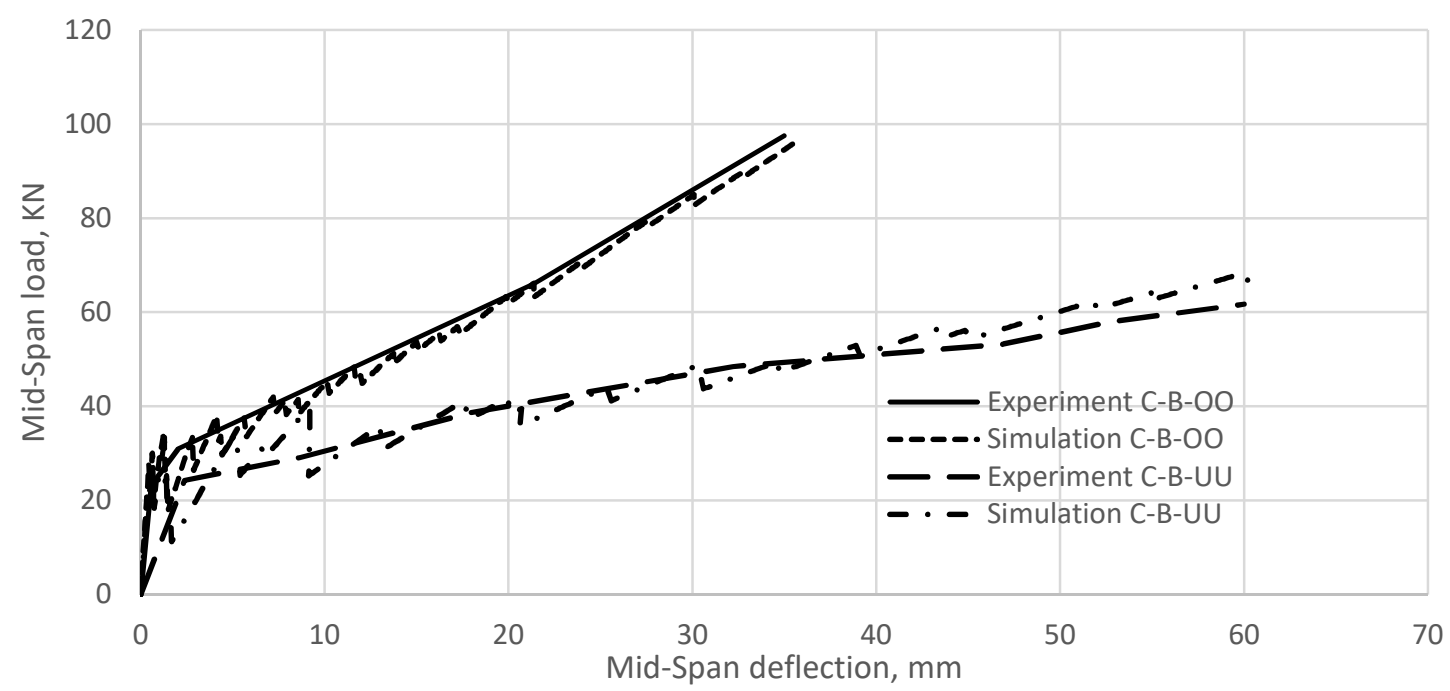

Figure 10. Load deflection curves of 2-span beams (experimental and theoretical)

\section{IV.CONCLUSION}

An efficient numerical modelling framework for basalt rebar reinforced concrete is proposed. The method is based on precomputed database with stiffness characteristics such as flexural stiffness EI of the beam. Two alternative methods for computation of database are proposed. The first method is based on extended multi-scale finite element calculations for relatively thick beams, where shear cracks may appear. The second method is based on semi-analytical approach where the damage and cracks from bending moment and axial force are considered. The method is validated with experimental data from literature and showed good agreement with experiments.

\section{ACKNOWLEDGMENTS}

The research leading to these results has received the funding from Latvia state research programme under grant agreement "INNOVATIVE 


\section{MATERIALS AND SMART TECHNOLOGIES FOR ENVIRONMENTAL SAFETY, IMATEH".} Support for this work was provided by the Riga Technical University through the scientific Research Project Competition for Young Researchers No. ZP2016/1.

\section{REFERENCES}

[1] Atutis M., Valivonis J., Atutis E. Experimental study of concrete beams prestressed with basalt fiber reinforced polymers. Part I: flexural behavior and serviceability, Composite Structures, 2017, doi: http://dx.doi.org/10.1016/j.compstruct.2017.01.081

[2] Atutis E., Atutis M., Budvytis M., Valivonis J. Serviceability and Shear Response of RC Beams Prestressed with a Various Types of FRP Bars, Procedia Engineering, 172, 2017, pp 6067.

[3] Pawłowski D., Szumigała M. Flexural Behaviour of Fullscale Basalt FRP RC Beams - Experimental and Numerical Studies, Procedia Engineering, 108, 2015, pp. 518-525.

[4] Mahroug M.E.M., Ashour A.F., Lam D. Experimental response and code modelling of continuous concrete slabs reinforced with BFRP bars, Composite Structures, 107, 2014, pp. 664-674.

[5] He W., Wu T.F., Xu Y., Fu T.T. A thermodynamically consistent nonlocal damage model for concrete materials with unilateral effects, Computer Methods in Applied Mechanics and Engineering, 297, 2015, pp. 371-391.

[6] Richard B., Ragueneau F., Cremona C., Adelaide L. Isotropic continuum damage mechanics for concrete under cyclic loading: Stiffness recovery, inelastic strains and frictional sliding, Engineering Fracture Mechanics, 77(8), 2010, pp. 1203-1223.

[7] Roth S.N., Léger P., Soulaïmani A. A combined XFEMdamage mechanics approach for concrete crack propagation, Computer Methods in Applied Mechanics and Engineering, 283, 2015, pp. 923-955.

[8] Kurumatani M., Terada K., Kato J., Kyoya T., Kashiyama K. An isotropic damage model based on fracture mechanics for concrete, Engineering Fracture Mechanics, 155, 2016, pp. 4966.

[9] Jirásek M., Patzák B. Consistent tangent stiffness for nonlocal damage models, Computers \& Structures, 80(14-15), 2002, pp. 1279-1293.

[10] Ren M., Cong J., Wang B., Guo X. Extended multiscale finite element method for small-deflection analysis of thin composite plates with aperiodic microstructure characteristics, Composite Structures, 160, 2017, pp. 422434.

[11] Temizer İ., Wu T., Wriggers P. On the optimality of the window method in computational homogenization, International Journal of Engineering Science, 64, 2013, pp. 66-73.

[12] Liu H., Zhang H.W. A p-adaptive multi-node extended multiscale finite element method for 2D elastostatic analysis of heterogeneous materials, Computational Materials Science, 73, 2013, pp. 79-92.

[13] Liu H., Lv J. An equivalent continuum multiscale formulation for 2D geometrical nonlinear analysis of lattice truss structure, Composite Structures, 160, 2017, pp. 335-348. 